\title{
Neonatal circumcision and invasive squamous cell carcinoma of the penis: a report of 3 cases and a review of the literature
}

\author{
Elantholi P. Saibishkumar, MD; ${ }^{*}$ Juanita Crook, MD; ${ }^{*}$ Joan Sweet, $M D^{\dagger}$
}

\begin{abstract}
Neonatal circumcision is widely considered to have a protective effect against the development of squamous cell carcinoma of the penis in later life. We report 3 cases of squamous cell carcinoma in men who were circumcised as neonates. The 3 men, aged 49, 55 and 64 years, presented for consideration of brachytherapy. The tumour stage was T3 in 1 case and T1 in the others. The tumours were moderately differentiated in 2 cases and well differentiated in 1 case. All 3 men had a remote history of penile condylomata acuminatum 20-30 years earlier. Oncogenic human papillomavirus (HPV) was found in the tumour specimen in 1 case. All 3 were treated with brachytherapy to the primary tumour on the glans. In 2 cases, subsequent staging inguinal node dissection was indicated because of the grade and stage of the primary tumour. A history of remote HPV infection should increase the index of suspicion for any nonhealing penile lesion, despite a history of neonatal circumcision.
\end{abstract}

CUAJ 2008;2(1):39-42

\section{Introduction}

Globally, about $25 \%$ of males are circumcised for cultural, religious or medical reasons. ${ }^{1}$ There is evidence that circumcision is protective against infant urinary tract infections and certain sexually transmitted infections (STIs) including HIV. ${ }^{1-3}$ Neonatal circumcision has been cited as being "highly protective" against invasive penile carcinoma. ${ }^{4}$

One of the most prevalent STIs is infection by human papillomavirus (HPV). HPV DNA has been detected in 49\%-80\% of invasive squamous cell cancers of the penis, ${ }^{5-8}$ with the known oncogenic subtypes 16 and 18 being the most common, although HPV 33 has also been reported. ${ }^{9}$

We report 3 cases of invasive penile cancer in men who were circumcised as neonates but had a remote history of HPV infection in young adult life.

\section{The cases}

Between April 2002 and September 2006, 3 cases of invasive squamous cell carcinoma of the penis occurred in men who were circumcised as neonates out of a total of 21 cases of nonmetastatic penile cancer referred to the Princess Margaret Hospital for brachytherapy during that period.

\section{Case 1}

A 55-year-old man presented with a nonhealing lesion on his glans penis that had not responded to steroid creams. He was circumcised as an infant but had a history of penile warts 25 years earlier. He was a former smoker and denied any high-risk sexual behaviour. There was no history of trauma to the penis, but he had attributed the lesion to friction induced by bike shorts. On examination, an erythematous lesion measuring $1.5 \mathrm{~cm} \times 2.4 \mathrm{~cm}$ was present on the ventral surface of the glans near the urethral meatus. The depth of the lesion was 2-3 mm. Biopsy, performed 18 months after the onset of the symptoms, revealed a moderately differentiated squamous cell carcinoma. In situ hybridization did not detect HPV DNA in the biopsy specimen. There was no clinical evidence of inguinofemoral lymphadenopathy (T1N0). The patient was treated with interstitial brachytherapy in April 2002. Abdomino-pelvic CT scan in May 2002 showed a $3.0 \mathrm{~cm} \times 1.3 \mathrm{~cm}$ lymph node in the right inguinal region. The patient underwent bilateral superficial inguinal dissection in June 2002, but all the lymph nodes were negative for malignancy. Four years after the procedure, he was disease-free with good cosmesis and sexual function.

\section{Case 2}

A 49-year-old man presented with a 6-month history of ulceration of his glans penis, which was treated with antiviral, antifungal and antibiotic agents without response. He developed a deviated urinary stream, and in November 2001 underwent biopsy, which showed diffuse inflammation of epidermis and presence 
of atypical keratinocytes consistent with Bowen's disease. A repeat biopsy in January 2002 showed invasive, moderately differentiated, keratinizing squamous cell carcinoma (Fig. 1). We tested for HPV DNA using the Polymerase Chain Reaction (PCR) technique but the results were inconclusive. He was circumcised at birth. He denied any history of STIs or multiple sexual partners, and reported being a heavy smoker with a 25-pack year history. He had been treated for a warty lesion on the glans with podophyllum resin at the age of 22 years and subsequently with liquid nitrogen at the age of 27 years. On examination, there was an ulcerative lesion on the ventral aspect of the glans with a rolled edge extending beyond the coronal sulcus proximally and reaching almost to the meatus distally. The lesion was impinging on the urethra just proximal to the meatus, as seen on urethroscopy, but the urethral mucosa appeared intact. The maximum dimension was $2.5 \mathrm{~cm}$. There were suspicious nodes in the right inguinal region on clinical examination but CT scan was negative. The patient was clinically staged as $\mathrm{T} 3 \mathrm{NO}$ and underwent brachytherapy in January 2002. Bilateral superficial inguinal lymph node dissection in May 2002 was negative for malignancy. He developed soft tissue ulceration on the ventral surface of the glans, which was treated with hyperbaric oxygen therapy with satisfactory results. As of January 2007, 5 years

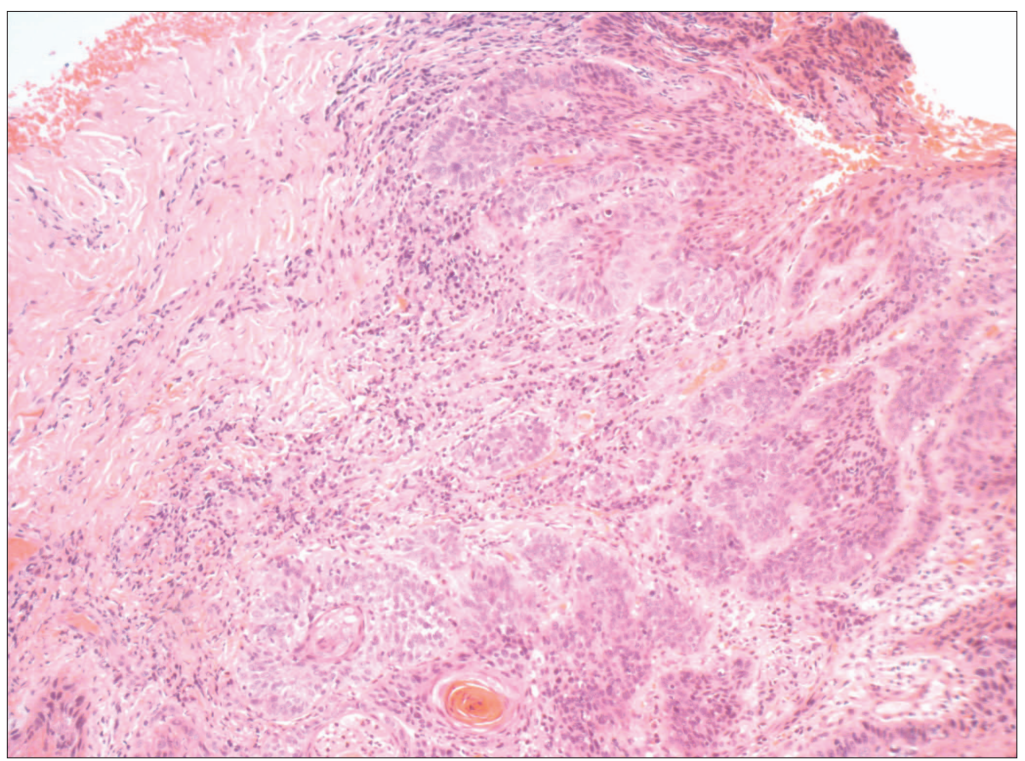

Fig. 1. Histology of the biopsy of penile squamous mucosa with moderately differentiated invasive keratinizing squamous cell carcinoma (hematoxylin-eosin staining, original magnification 100x). after brachytherapy, he remained disease-free with an intact penis and intact erectile function.

\section{Case 3}

A 64-year-old man presented with a history of a lesion on his glans penis for 18 months, which had not responded to steroid and antifungal creams. Biopsy was performed in August 2006 and showed squamous cell carcinoma in situ with cancer extending to the margin of resection. Deeper invasion could not be excluded owing to inadequate sampling. PCR was positive for HPV subtype 16 DNA. The patient was circumcised as an infant and had never smoked, but he had a history of penile condyloma acuminatum 20 years earlier that was treated with podophyllum resin. He denied any high-risk sexual behaviour. On examination, there was an erythematous, slightly elevated lesion measuring $1 \mathrm{~cm}$ on the glans adjacent to the urethral meatus. Bilateral inguinal regions were clinically clear (T1N0). He underwent brachytherapy in September 2006 and remains disease-free with good function.

The common findings in all 3 men were neonatal circumcision, a history of penile condyloma acuminatum in early adult life and then the development of invasive penile cancer 20-25 years later. In each instance diagnosis was delayed for 6-18 months, presumably owing to the assumption that penile cancer is exceedingly rare in a circumcised penis. All 3 men were successfully treated, fortunately preserving penile function and morphology, using pulsed dose rate (PDR) brachytherapy. Details of the brachytherapy technique and results from our institution are described elsewhere. ${ }^{10-12}$ The dose prescribed was 60 Gy delivered over $4.5-5$ days. Two patients underwent modified bilateral inguinal dissection because of either tumour stage or differentiation as per our clinical experience and guidelines. ${ }^{10-13}$ Both patients had negative lymph nodes on pathological examination. All 3 men remain disease-free and have an intact penis and intact erectile function.

\section{Discussion}

Neonatal circumcision has been considered protective against invasive penile cancer. An extensive review of 1103 cases of penile cancer reported in 1932 failed to detect a single case among men 
circumcised as neonates. ${ }^{14}$ With reported benefits including prevention of urinary tract infections, STIs and invasive penile cancer, ${ }^{1-4,14}$ neonatal circumcision became a routine practice in North America. Over the next 6 decades, there were 12 published articles, each reporting a single case of invasive penile squamous cell carcinoma following neonatal circumcision. ${ }^{15-26}$ Schoen and colleagues ${ }^{4}$ reviewed the cancer registry of Northern California for the incidence of invasive penile cancer from 1954 to 1997 and found that only 2 of 89 cases occurred in neonatally circumcised men. We report 3 cases of invasive penile cancer occurring in neonatally circumcised men referred to our centre between 2002 and 2006.

Circumcision performed beyond infancy may not offer protection against invasive penile cancer. ${ }^{27-30}$ Bissada and colleagues ${ }^{27}$ reported the largest series of invasive penile cancer (15 cases) in men circumcised after childhood. Recently, Seyam and others ${ }^{28}$ updated this series with 22 additional cases. In these men, circumcision was performed in an unhygienic manner Tihamah circumcision - which led to scarring and subsequent development of cancer in these scars. Tumours were locally advanced at presentation and were treated surgically. Paradoxically, Brinton and colleagues ${ }^{29}$ reported a case-control series in which circumcised men had a higher risk of developing penile cancer than uncircumcised men. However, as in the cases reported by Bissada and colleagues ${ }^{27}$ and Seyam and colleagues, ${ }^{28}$ none of the reported cases had had circumcision at birth and more than one-half had this procedure done within 5 years preceding the diagnosis of penile cancer. Circumcision performed to relieve symptoms such as phimosis or discharge may well be associated with a premalignant condition.

Circumcision, even when performed neonatally, may not offer protection against the development of carcinoma in situ. ${ }^{31,32}$ Schoen and colleagues ${ }^{4}$ reported that more than $15 \%$ of patients with in situ cancer were circumcised at birth. In the case-control series by Maden and colleagues, ${ }^{5}$ $20 \%$ of cases had neonatal circumcision, but both invasive and in situ penile cancers were considered together. It is not clear how many men with neonatal circumcision developed invasive penile cancer, compared with in situ cancer.

Our report of 3 men with invasive penile cancer, all circumcised at birth, is noteworthy in that all 3 had a history of benign penile warts 20-25 years earlier. The history of penile warts has been reported in case-control studies to be a major risk factor for the development of penile cancer, with an odds ratio ranging from 5.9 to $7.6 .{ }^{5,8}$ Case reports have also documented invasive penile cancer developing in men circumcised at birth. ${ }^{15,16,26}$ The most commonly attributed infective agents in penile cancer are HPV 16 and 18..$^{5-8,33}$ HPV 16 DNA was demonstrated by PCR in the biopsy specimen of 1 patient in our series. Even though the reported incidence of high-risk HPV DNA generally ranges from $49 \%-80 \%$ in invasive penile cancer, ${ }^{5-8,33}$ it can be as low as $15 \% .{ }^{34}$ Certainly, our patients' histories would implicate HPV causation, even in the absence of PCR proof.

These 3 men presented at a relatively young age (49, 55 and $64 \mathrm{yr}$ ). Two recent case reports of invasive penile cancer ${ }^{25,26}$ also showed a trend toward occurrence in younger men (34 and $37 \mathrm{yr}$, respectively). All 3 men were successfully treated by brachytherapy, with or without inguinal node dissection, achieving penile preservation without locoregional recurrence, despite a significant delay from onset of symptoms to diagnosis. The delay in these cases was not attributable to the patient, rather to the assumption among physicians that neonatal circumcision offers an absolute protection against invasive penile cancer. ${ }^{23-25}$

Etiologic factors implicated in the causation of invasive penile cancer other than lack of circumcision and genital warts include use of tobacco products, history of penile rashes or trauma, poor hygiene, other STIs (e.g., syphilis and herpes), urinary tract infections, and the presence of high-risk sexual behaviour or multiple sexual partners. $5,8,29,35,36$ One of our patients was a heavy smoker with a 25-pack year history. All 3 men were educated beyond high school level and stated that they maintained proper hygiene. All denied high-risk sexual behaviour and had long-standing monogamous relationships. Even though there is evidence for the association of these risk factors with penile cancer, the exact role and pathogenesis are still not clear. Evidence is evolving for the multiple independent pathways of penile carcinogenesis, which may include mutations in the p53 gene other than HPV infection. , $37^{37}$

Based on our cases and the literature, it is prudent to conclude that circumcision, even when performed neonatally, does not offer absolute 
protection against invasive penile cancer. Neonatal circumcision may still be one of the major protective factors against penile cancer, but it should not prevent the physicians from having a high index of suspicion when there is a nonhealing penile lesion. Biopsies should be undertaken sooner rather than later especially when there is a history of remote HPV infection or other known risk factors for penile cancer.

From the *Department of Radiation Oncology, University Health Network, Princess Margaret Hospital, Toronto, Ont., and the †Department of Pathology, University Health Network, Toronto, Ont.

This article has been peer reviewed.

Competing interests: None declared.

\section{References}

1. Wiswell TE. Routine neonatal circumcision: A reappraisal. Am Fam Physician 1990;41: 859-63.

2. Schoen EJ. The relationship between circumcision and cancer of the penis. CA Cancer J Clin 1991:41:306-9.

3. Moses S, Bailey RC, Ronald AR. Male circumcision: assessment of health benefits and risks. Sex Transm Infect 1998;74:368-73.

4. Schoen EJ, Oehrli M, Colby CJ, et al. The highly protective effect of newborn circumcision against invasive penile cancer. Pediatrics 2000;105:E36.

5. Maden C, Sherman KJ, Beckmann AM, et al. History of circumcision, medical conditions, and sexual activity and risk of penile cancer. J Natl Cancer Inst 1993;85:19-24.

6. Levi JE, Rahal P, Sarkis AS, et al. Human papillomavirus DNA and p53 status in penile carcinomas. Int J Cancer 1998;76:779-83.

7. Picconi MA, Eijan AM, Distefano AL, et al. Human papillomavirus (HPV) DNA in penile carcinomas in Argentina: analysis of primary tumors and lymph nodes. J Med Virol 2000;61:65-9.

8. Daling JR, Madeleine MM, Johnson LG, et al. Penile cancer: importance of circumcision, human papillomavirus and smoking in insitu and invasive disease. Int I Cancer 2005; 116:606-16.

9. Amerio $\mathrm{P}, \mathrm{Offidani} \mathrm{A}$, Cellini A, et al. Well-differentiated squamous cell carcinoma of the penis associated with HPV type 33. Int I Dermatol 1998;37:128-30.

10. Crook J, Grimard L, Tsihlias J, et al. Interstitial brachytherapy for penile cancer: an alternative to amputation. J Urol 2002;167:506-11.

11. Crook JM, Jezioranski J, Grimard L, et al. Penile brachytherapy: results for 49 patients. Int J Radiat Oncol Biol Phys 2005;62:460-7.

12. Crook JM. Radiation therapy for penile cancer. In: Vogelzang NJ, Scradino PT, Shipley WU, et al, editors. Comprehensive textbook of genitourinary oncology. Philadelphia: Lippincott Williams \& Wilkins; 2006. p. 819-26.

13. Tauskky D, Crook J, Al Ghamdi A, et al. Treatment of the inguinal regions in penile cancer: a review of the literature and treatment proposal. Can J Urol 2006;13:2978-83.

14. Wolbarst AL. Circumcision and penile cancer. Lancet 1932;1:150-3.

15. Dean AL Jr. Epithelioma of the penis in a Jew who was circumcised in infancy. Trans Am Assoc Genitourin Surg 1936; 29: 493-9.

16. Marshall VF. Typical carcinoma of the penis in a male circumcised in infancy. Cancer 1953;6:1044-5.

17. Reitman PH. An unusual case of penile carcinoma. J Urol 1953;69:547-9.

18. Paquin AJ Jr, Pearce JM. Carcinoma of the penis in a man circumcised in infancy. J Urol 1955;74:626-7.

19. Amelar RD. Carcinoma of the penis due to trauma occuring in the male patient circumcised at birth. J Urol 1956;75:728-9.

20. Ledlie RC, Smithers DW. Carcinoma of the penis in a man circumcised in infancy. J Urol 1956;76:756-7.

21. Kaufman JJ, Sternberg TH. Carcinoma of the penis in a circumcised man. J Urol 1963:90:449-50.

22. Melmed EP, Pyne JR. Carcinoma of the penis in a Jew circumcised in infancy. Br J Surg 1967;54:729-31.

23. Leiter E. Lefkovitls AM. Circumcision and penile carcinoma. N Y State J Med 1975;75:1520-2.

24. Boczko S, Freed S. Penile carcinoma in circumcised males. N Y State J Med 1979:79:1903-4.

25. Rogus BJ. Squamous cell carcinoma in a young circumcised man. J Urol 1987;138:861-2.

26. Kanik AB, Lee J, Wax F, et al. Penile verrucous carcinoma in a 37 year old circumcised man. J Am Acad Dermatol 1997;37:329-31.

27. Bissada NK, Morcos RR. El-Senoussi. Post-circumcision carcinoma of the penis. I. Clinical aspects. J Urol 1986;135:283-5.

28. Seyam RM, Bissada NK, Mokhtar AA, et al. Outcome of penile cancer in circumcised men. J Urol 2006;175:557-61.

29. Brinton $L A$, Jun-Yao $L$, Shou-de $R$, et al. Risk factors for penile cancer: results from a case-control study in China. Int J Cancer 1991;47:504-9.

30. Magoha GA, Kaale RF. Epidemiological and clinical aspects of carcinoma of penis at Kenyatta National Hospital. East Afr Med J 1995; 72:359-61.

31. Cold CJ, Storms MR, Van Howe RS. Carcinoma in situ in a 76 year old circumcised man. J Fam Pract 1997;44:407-10.

32. Ross BS, Levin VJ, Dixon C, et al. Squamous cell carcinoma of the penis in a circumcised man: a case for dermatology and urology, and review of literature. Cutis 1998; 61:41-3.

33. Griffiths TRL, Mellon JK. Human papillomavirus and urological tumors: I. Basic science and role in penile cancer. BJU Int 1999;84:579-86.

34. Chan KW, Lam KY, Chan AC, et al. Prevalence of human papillomavirus types 16 and 18 in penile carcinoma: a study of 41 cases using PCR. J Clin Pathol 1994;47:823-6.

35. Hellberg D, Valentin J, Eklund $T$, et al. Penile cancer: Is there an epidemiological role for smoking and sexual behavior? BMJ 1987:295:1306-8.

36. Harish K, Ravi R. The role of tobacco in penile carcinoma. Br J Urol 1995;75:375-7.

37. Rubin MA, Kleter $B$, Zhou $M$, et al. Detection and typing of human papillomavirus DNA in penile carcinoma: evidence for multiple independent pathways of penile carcinogenesis. Am J Pathol 2001;159:1211-8.

Correspondence: Dr. J. Crook, Princess Margaret Hospital, 610 University Ave.., Toronto ON M5G 2M9; juanita.crook@rmp.uhn.on.ca 